\title{
Structured reporting in radiology: a systematic review to explore its potential
}

\author{
J. Martijn Nobel ${ }^{1,2} \cdot$ Koos van Geel $^{2,3} \cdot$ Simon G. F. Robben ${ }^{1,2}$
}

Received: 3 May 2021 / Revised: 15 August 2021 / Accepted: 13 September 2021 / Published online: 15 October 2021

(c) The Author(s) 2021

\begin{abstract}
Objectives Structured reporting (SR) in radiology reporting is suggested to be a promising tool in clinical practice. In order to implement such an emerging innovation, it is necessary to verify that radiology reporting can benefit from SR. Therefore, the purpose of this systematic review is to explore the level of evidence of structured reporting in radiology. Additionally, this review provides an overview on the current status of SR in radiology.

Methods A narrative systematic review was conducted, searching PubMed, Embase, and the Cochrane Library using the syntax 'radiol*' AND 'structur*' AND 'report*'. Structured reporting was divided in SR level 1, structured layout (use of templates and checklists), and SR level 2, structured content (a drop-down menu, point-and-click or clickable decision trees). Two reviewers screened the search results and included all quantitative experimental studies that discussed SR in radiology. A thematic analysis was performed to appraise the evidence level.

Results The search resulted in 63 relevant full text articles out of a total of 8561 articles. Thematic analysis resulted in 44 SR level 1 and 19 level 2 reports. Only one paper was scored as highest level of evidence, which concerned a double cohort study with randomized trial design.

Conclusion The level of evidence for implementing SR in radiology is still low and outcomes should be interpreted with caution.

Key Points

- Structured reporting is increasingly being used in radiology, especially in abdominal and neuroradiological CT and MRI reports.

- SR can be subdivided into structured layout (SR level 1) and structured content (SR level 2), in which the first is defined as being a template in which the reporter has to report; the latter is an IT-based manner in which the content of the radiology report can be inserted and displayed into the report.

- Despite the extensive amount of research on the subject of structured reporting, the level of evidence is low.
\end{abstract}

Keywords Radiology $\cdot$ Reports $\cdot$ Neoplasm staging $\cdot$ Magnetic resonance imaging $\cdot$ Multidetector computed tomography

\section{Abbreviations}

ESR European Society of Radiology

PACS Picture Archiving and Communication System

J. Martijn Nobel

martijn.nobel@mumc.nl

1 Department of Radiology, Maastricht University Medical Center+, Postbox 5800, 6202 AZ Maastricht, the Netherlands

2 Department of Educational Development and Research and School of Health Professions Education, Maastricht University, Maastricht, the Netherlands

3 Department of Medical Imaging of Zuyderland Medical Center, Heerlen, the Netherlands
PRISMA Preferred Reporting Items for Systematic reviews and Meta-Analyses

RSNA Radiological Society of North America

SR Structured reporting

\section{Introduction}

The area of radiology is an ever innovating field with new applications, such as speech recognition systems and the introduction of Picture Archiving and Communication System (PACS), leading to digitalization and new possibilities in radiology reporting $[1,2]$. The recent introduction of different types of structured reporting (SR) further 
accelerates initiatives in the field of reporting, and many radiology departments use some sort of SR already [3]. The magnitude of this trend and its promotion by large radiological societies, such as the Radiological Society of North America (RSNA) and the European Society of Radiology (ESR), suggests that this way of reporting is promising and that implementation of SR in clinical practice should be seriously considered [4, 5]. Overall, SR has been thought to be the key to improve clinical and radiological workflow.

The main goal of implementing SR seems to be enhancing the content of the radiological report as well as the reporting process itself. Due to increasing imaging possibilities, larger data sets and the availability of more specific treatments, details become ever more important. The radiological report should arrange this huge amount of information into a readable (legible) text containing the most accurate and specific information that is needed to make accurate decisions to treat the patient best. This renders the radiological reporting process more complicated and time consuming.

To accommodate this increasing demand of information, several tools have been proposed to improve the quality of the radiological report. Standardization tools (RECIST (Response Evaluation Criteria in Solid Tumors), Fleischner glossary, the RADS (Reporting And Data System) collection) [6-8], are created to be more accurate on describing pathology and its extension or evolution, to ensure that the content of the report is accurate. On the other hand, reporting tools, such as structured reporting and reporting guidelines, are constructed in order to enhance the reporting process; this concept is in literature generally referred to as "structured reporting."

However, before implementation of SR, it is necessary to provide evidence to justify its introduction and implementation in the clinical workflow with a systematic review. As there is a plethora of definitions and interpretations of SR present in literature, a clear definition had to be determined for this review. The definition "structured reporting is an IT-based method to import and arrange the medical content into the radiological report," as coined by Nobel et al. [9], was used. The main purpose of this systematic review is to explore the level of evidence of structured reporting. Additionally, this review provides an overview on the current status of SR in radiology.

\section{Materials and methods}

A systematic search was conducted according to the Preferred Reporting Items for Systematic reviews and MetaAnalyses (PRISMA) criteria [10], and results were further categorized using a thematic analysis approach [11]. Results were analyzed and interpreted consistently with a textual narrative synthesis to visualize the similarities and differences among various methodologies in study design [12]. The next step was to determine the level of evidence of the studies. Because of the heterogeneity in study design, the simplified grading system (level A/B/C) according to Siwek et al. [13] was used to determine the strength of evidence on which outcomes were based. Randomized controlled trials are considered level A. Level B studies consist of all other evidence except for expert opinions or commentaries, which are level C. The groups were ordered on publication year followed by an alphabetical order. In case of discrepancy, consensus was reached between two authors (J.M.N. and K.G.).

\section{Literature review protocol}

A literature search was conducted by searching PubMed, Embase, and the Cochrane Library up to 10 August 2020. To include relevant papers, a wide search strategy was applied using the combination of the synonyms of 'radiology', 'structure' and 'reporting' (radiol* AND structur* AND report*).

\section{Eligibility and study selection}

All quantitative experimental studies that discussed SR in radiology have been included. After removing duplicates, title and abstract were independently screened on relevance by two authors. The following articles were excluded: articles that did not discuss structured reporting in radiology; comments or expert opinions (level C [13]); articles not in English, German, or Dutch; or those without full text availability. Bibliographies of included studies were searched in order to find additional relevant papers.

\section{Definition of structured reporting (SR)}

The definition "structured reporting is an IT-based method to import and arrange the medical content into the radiological report" [9] was used to frame the field of interest. This definition acknowledges a difference between SR and standardized reporting. Standardized reporting refers to the increase of uniformity of the report content with standardization tools (e.g., RECIST, Fleischner glossary, the RADS collection [6-8]). SR refers to the use of specific tools (structured reporting or reporting guidelines) that can be used to properly build, structure, or fill the radiological report itself. This differentiation is necessary to be able to only include the right studies which change the reporting process and not studies that merely change, for instance, the vocabulary used.

Additionally, SR is subdivided into structured layout (SR level 1) and structured content (SR level 2) [9]. In this stratification model, structured layout (SR level 1) is defined as being a template or blueprint format in which the reporter 
has to report or has to adjust to. Structured content (SR level 2 ) is a manner in which the content of the radiology report can be inserted and displayed into the report (Fig. 1). As such, structured layout (e.g., templates and checklists) and structured content (e.g., drop-down menu, point-and-click or clickable decision trees) highlight the level of IT involvement when implementing SR. This subdivision is used to be able to categorize the types of SR found in the included studies.

\section{Results}

The literature search retrieved 4233, 6746, and 173 articles (total 11,152) from PubMed, Embase, and the Cochrane Library databases respectively. A total of 2591 duplicates were removed. Title and abstract of 8561 articles were assessed by J.M.N. and K.G., which resulted in 58 relevant articles. Full text was available for 56 articles. Bibliography search resulted in 7 additional studies, leading to a total of 63 studies that were included (Fig. 2 and Table 1). No reviews were found. Due to the heterogeneity of included studies, it was neither possible to perform a meta-analysis nor to pool the results.

\section{Thematic data analysis}

After inclusion, the 63 studies were grouped into structured layout (SR level 1) and structured content (SR level 2) groups (Fig. 3). Control group, intervention, subspecialty/ field, indication, modality, and outcome of each study were assigned. Because of heterogeneity in the structured layout group (SR level 1), this group of 44 studies was subdivided into three subcategories: (1) one template $(n=28),(2)$ multiple templates $(n=7)$, and (3) hypothetical research $(n=9)$ (Table 1, Fig. 3 and Fig. 4).

The first subcategory "one template" consists of studies that implement and compare only one template with a free text report comparison. An example can be an itemized template to report a specific clinical question, such as a magnetic resonance imaging (MRI) for brain tumor staging. The second subcategory "multiple templates" implemented several templates at once in their study before the comparison with free text reports was made. An example can be the implementation of several different templates for different clinical questions, such as implementing templates for computed tomography (CT), ultrasound, and X-ray concerning kidney stones, appendicitis, and heart failure. The third subcategory "hypothetical research" concerned studies that did not actually implement SR in clinical workflow, but assessed clinical or referring preferences on how to present the radiological information in the radiological report.

All 19 structured content (SR level 2) studies were interventional studies using an IT-based method to create the radiological report in the subcategories point-and-click system, pick list, clickable decision trees, drop-down and various (Table 1, Fig. 3 and Fig. 4).

As it is only possible, in an evidence-based manner, to accurately compare one structured reporting tool in one clinical interventional setting at once, only the studies implementing one template from the structured layout group and non-hypothetical studies have been used for further analysis. When not taking into account the hypothetical studies, nor the studies of the multiple template category, 28 studies remain on the structured layout level (SR level 1). All 19 structured content (SR level 2) studies were interventional
Fig. 1 Examples of different levels of structured reporting. SR level 1, structured layout: itemized, itemized-checklist; in these examples, the obligated items or possible options are already stated in the template to ensure its presence. SR level 2, structured content: drop-down menu, point-and-click/pick list; these are examples of IT-based tools to insert specific textual items into the radiological report, for instance with the use of a drop-down menu in which an option can be chosen out of a particular list, or by using a point-and-click/pick list which in turn can open a new pointand-click/pick list option in order to build the report

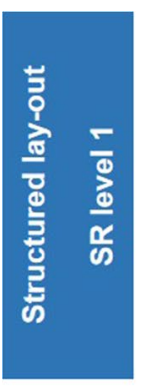

\section{Itemized}

Abdomen:

Liver:

Gallbladder:

Kidneys:

Aorta:

Impression:

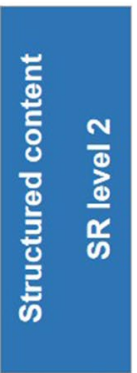

Itemized - checklist

Abdomen:

Normal aspect of the liver: no; mass in the liver Normal aspect of the gallbladder: yes / no

Normal aspect of the kidneys: yes / no

Normal size of the aorta: yes / no

Impression:

Mass in the liver

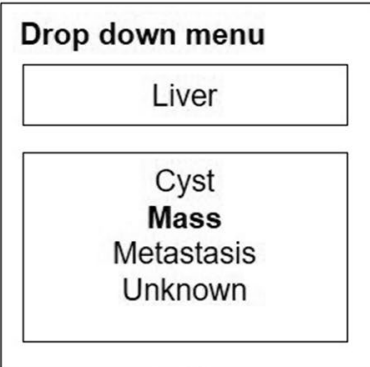

Point-and-click / pick list

Cyst

Liver

O

Mass $\checkmark$

Metastasis

Unknown

Segment 1
Segment 2
Segment 3
Segment 4a
Segment 4b
Segment $5 \mathrm{~V}$
Segment 6
Segment 7
Segment 8


Fig. 2 Search flow chart. SR, structured reporting

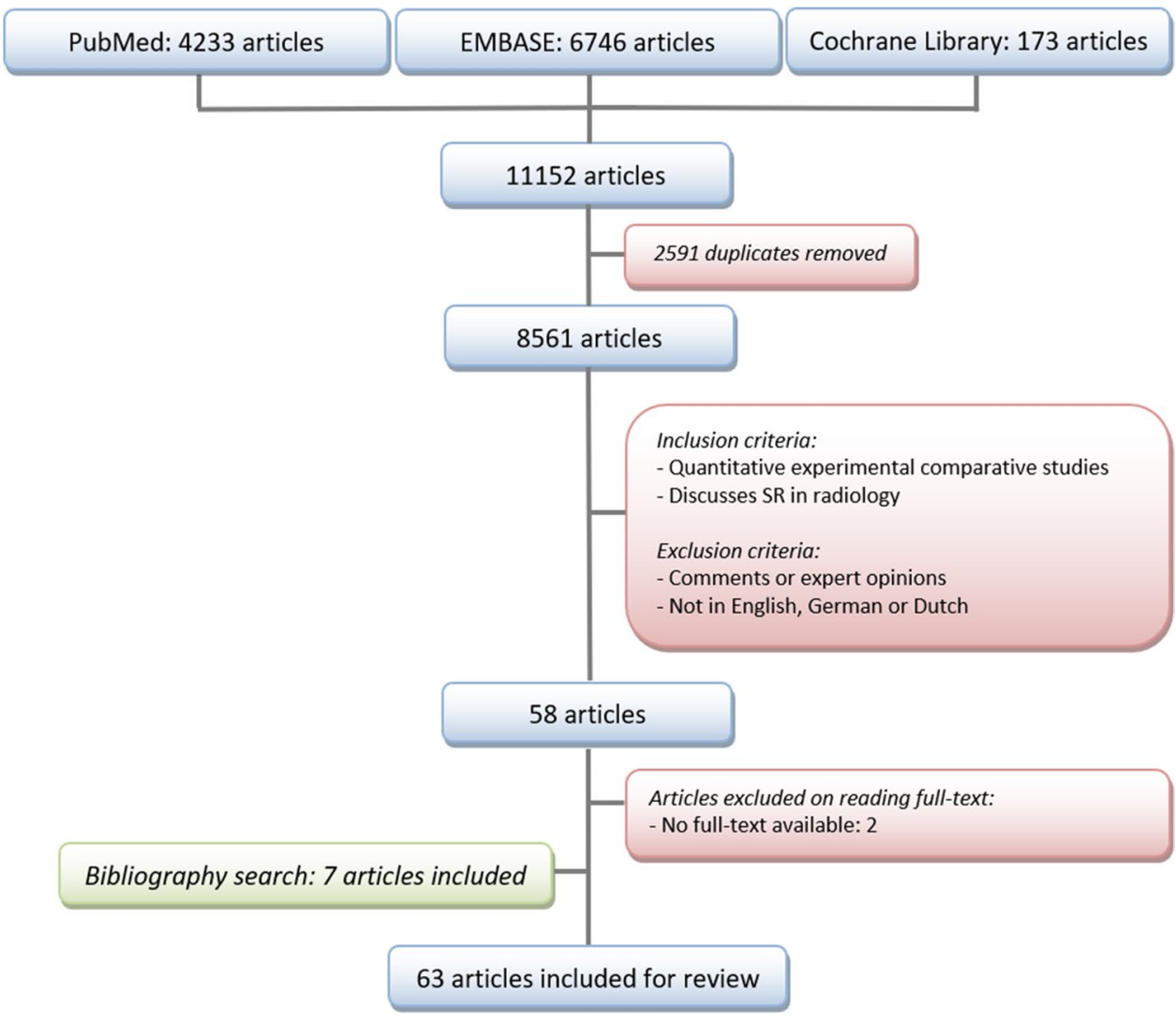

studies using one IT-based method to create the radiological report and were all suitable for further analysis (Table 1, Fig. 3 and Fig. 4). The remaining subcategories (one template SR level 1 and all SR level 2 studies) resulted in 47 studies (Fig. 3).

Further analysis of these 47 studies resulted in additional characteristics about subspecialty field and used modalities (Fig. $5 \mathrm{a}$ and b). Overall, CT and MRI modalities are mostly used on the subspecialties abdomen and neurology.

\section{Level of evidence}

Two papers (one single study) were scored as level A in the structured content group. All other studies in the structured layout and structured content group were scored as level B evidence (Fig. 6).

\section{Outcome}

The value of outcomes of the studies on structured reporting depends heavily on the level of evidence of these studies. Therefore, the main focus of this study was to determine the level of evidence. However, to create an overview of research done on SR in radiology, main outcomes of included SR studies have been summarized in Table 1 .

\section{Discussion}

The main goal of this narrative systematic literature review was to explore the level of evidence of all studies that try to enhance the radiological reporting process by using SR. This also resulted in an overview on the current status of SR in radiology and a summary of its outcomes. To our knowledge, this is the first paper to provide a systematic review of $\mathrm{SR}$ in radiology.

\section{Level of evidence}

A double-blinded, randomized controlled trial is considered the highest level of original research (not including systematic reviews or meta-analysis). In our literature search, the only study that approximates this level was the double cohort study with randomized trial design conducted by Johnson et al. $[58,59]$ and was therefore scored as level A evidence. They compared a point-and-click reporting system (SR level 2) with free text reporting in brain MRI in stroke patients in two papers. This study states that only the way of reporting varied in order to exclude all other interfering factors, thereby only investigating the effect of the change in reporting method. The remaining 61 studies were considered level B evidence, showing an overall low level of evidence. 
European Radiology (2022) 32:2837-2854

2841

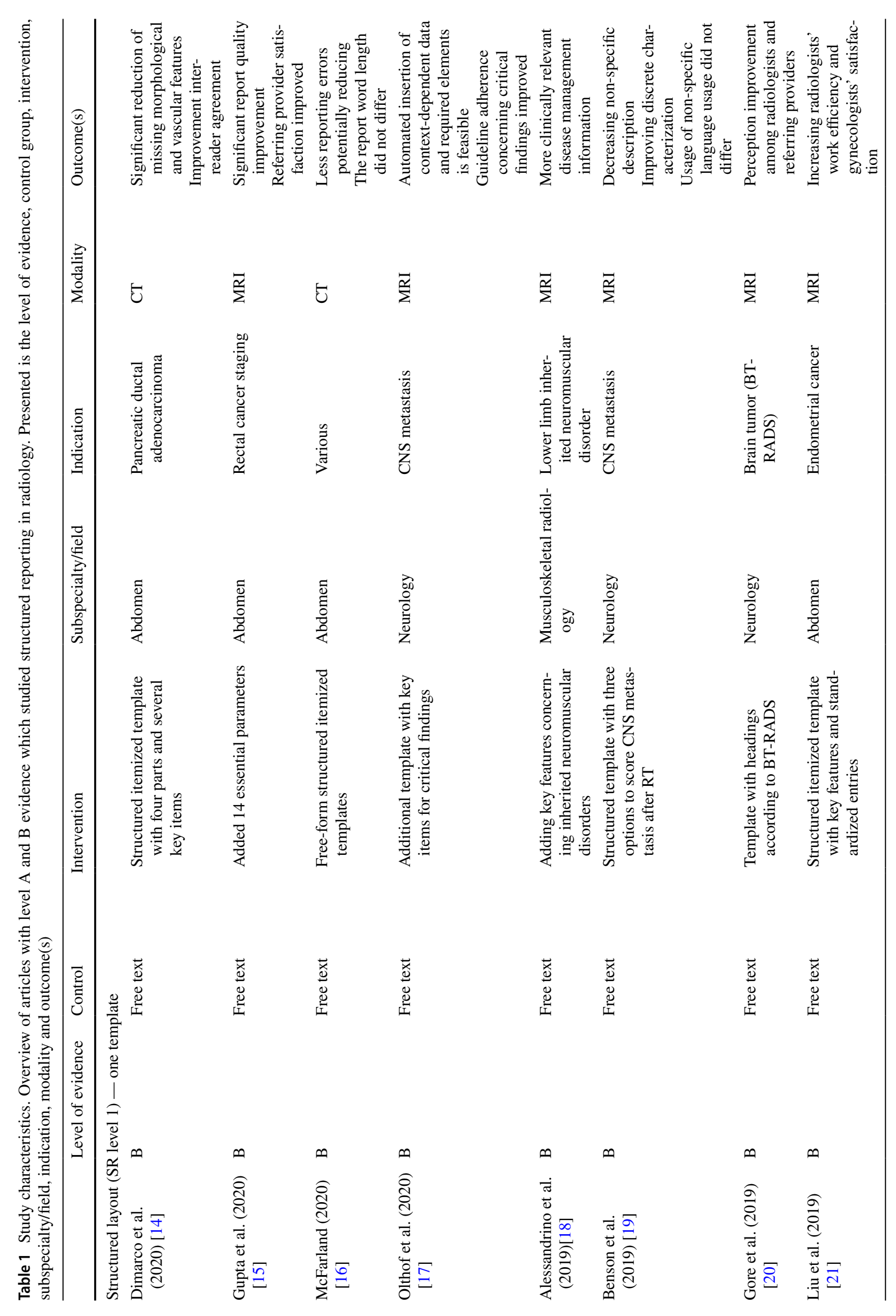

照 Springer 


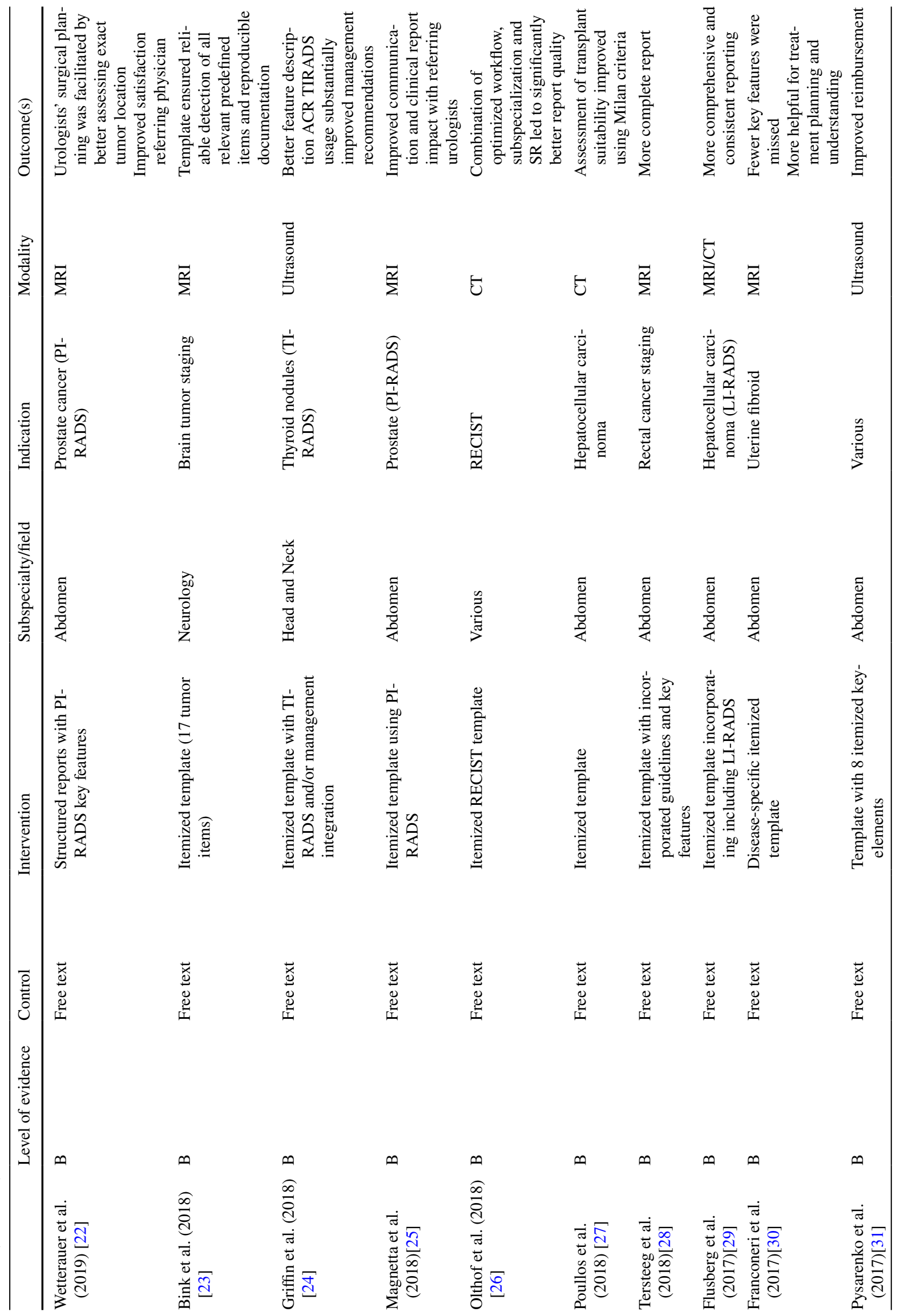




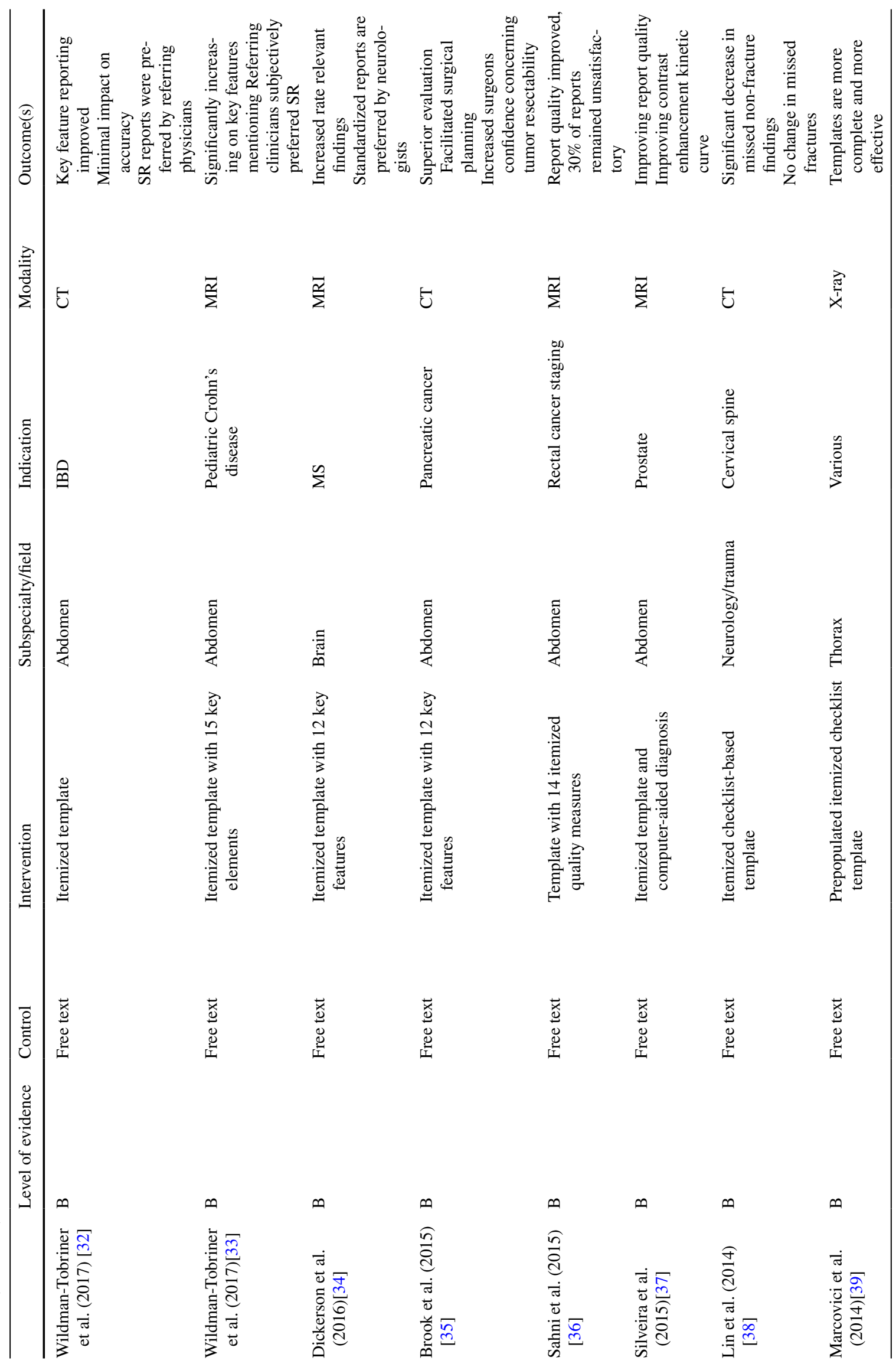




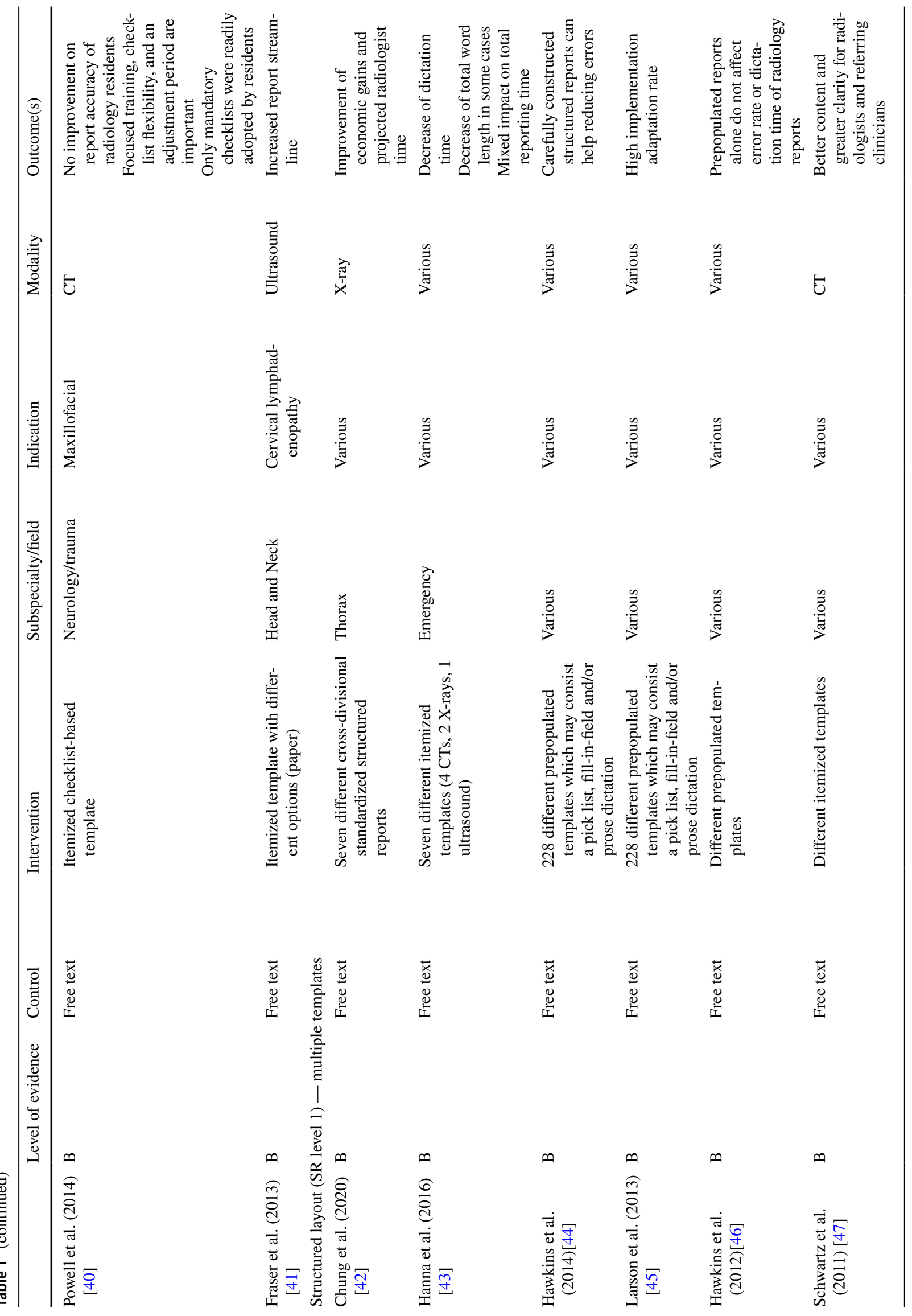




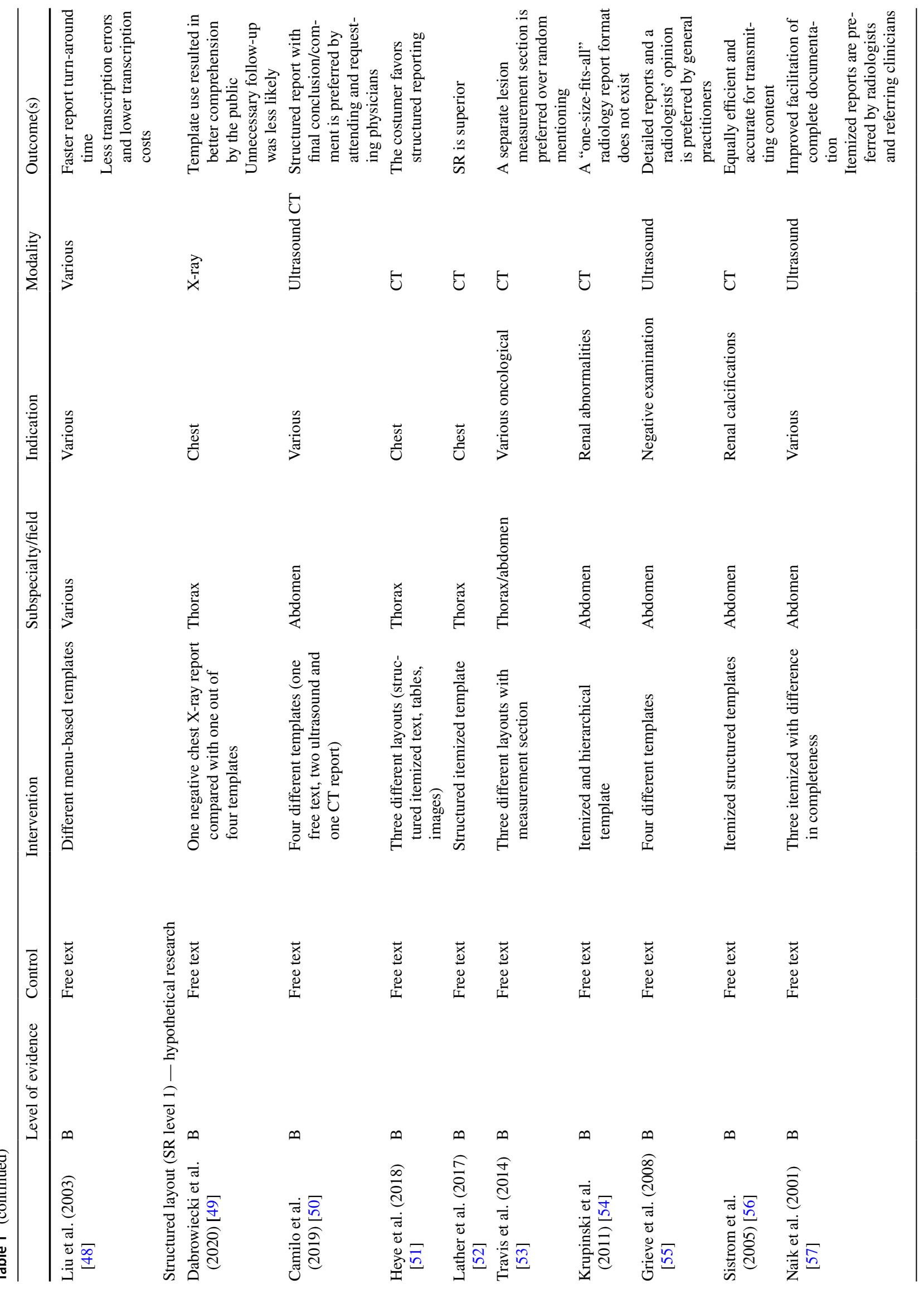




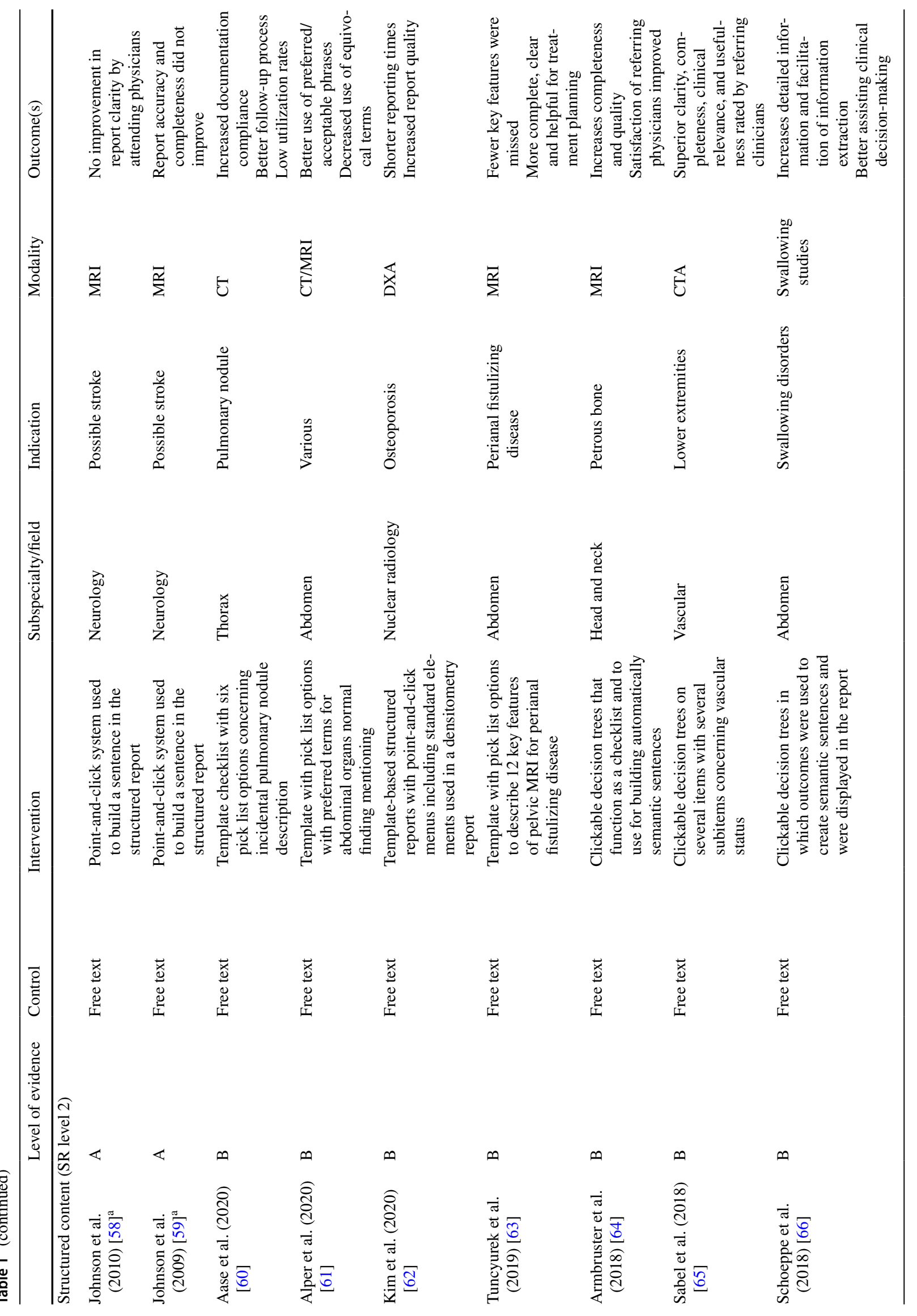




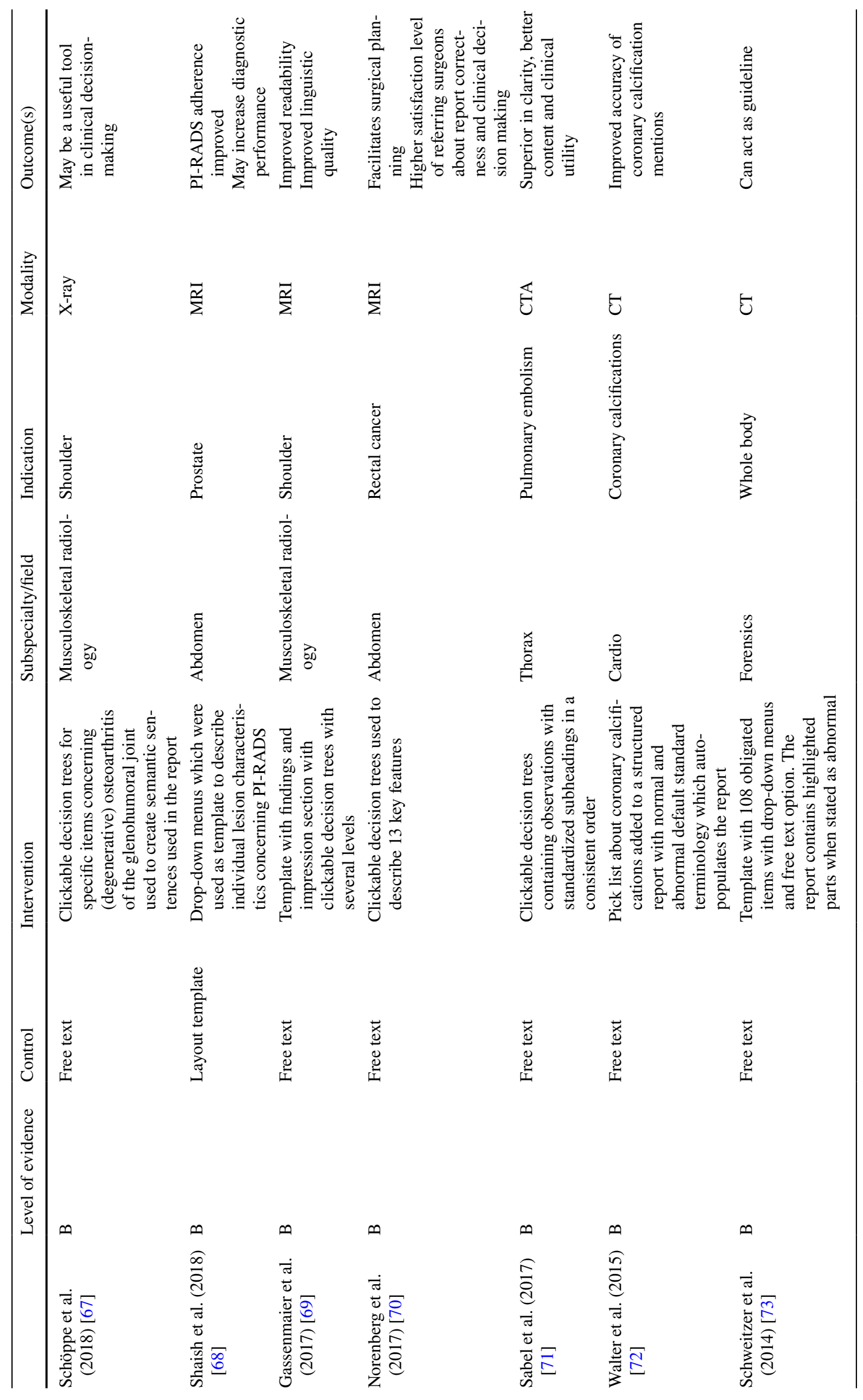




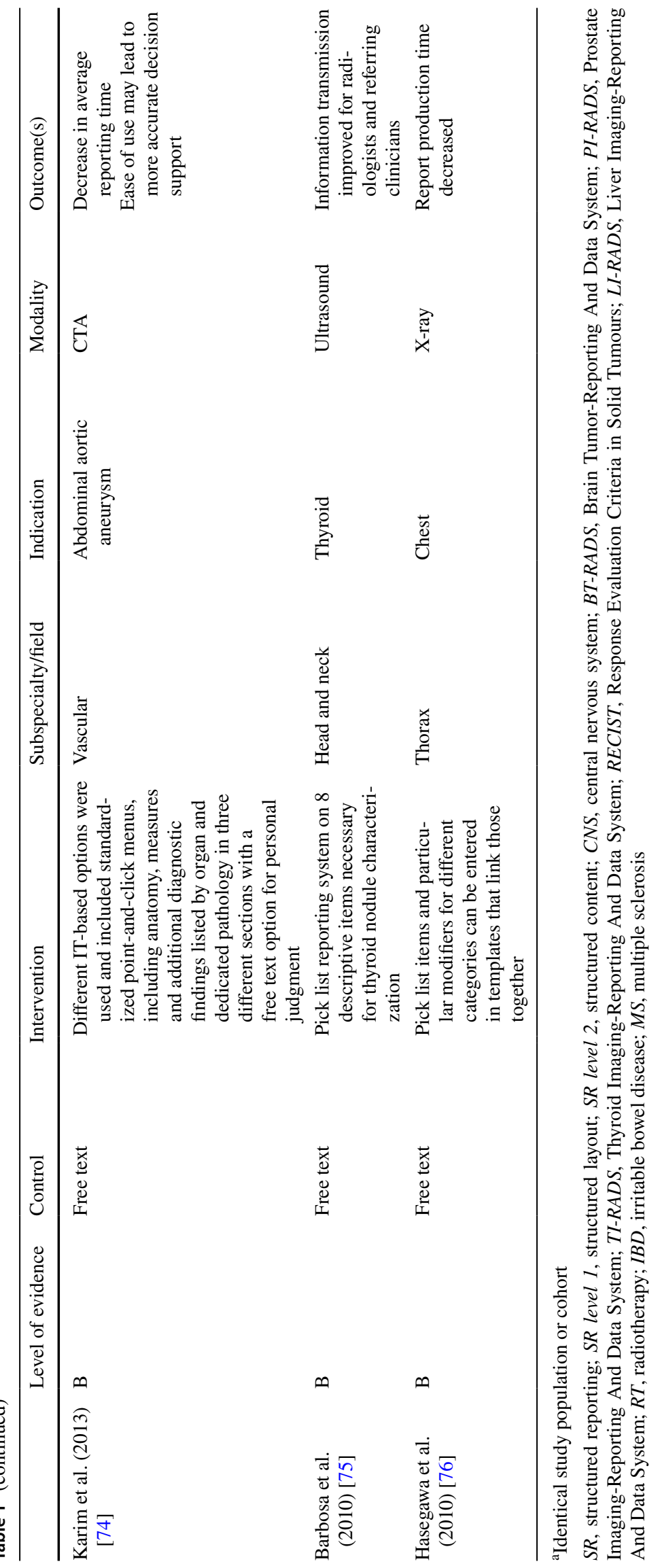


Fig. 3 Characteristics of included studies based on SR level. SR level 1, structured layout; SR level 2, structured content

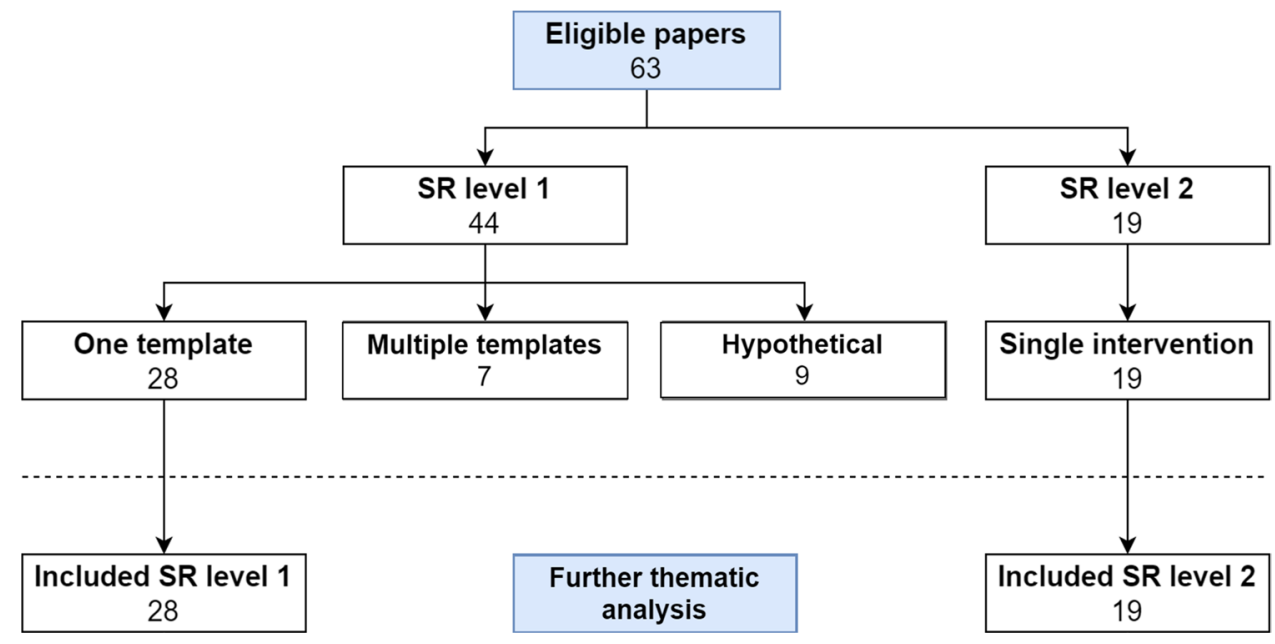

The hypothetical subcategory studies $(n=7)$ are not implementational but only exploratory of nature. The multiple template studies $(n=9)$ are considered low-level evidence, because it is virtually impossible to confidentially match outcomes to a particular way of reporting, when (a) introducing several templates or reports simultaneously, (b) using different levels of SR, for (c) trying to answer different clinical questions.

However, also the other subcategory studies (one template SR level 1 and all SR level 2 studies), except both level A studies, changed several factors during the implementation of SR, which again can result in some sort of confounding. For instance, many papers describe an expert meeting among radiologists and/or clinicians, or conducted a literature review in order to create a template or pick-list with adequate vocabulary, before implementing SR. This introduced an additional standardizing step next to the implementation of SR in the reporting routine. As a result, both the report content and the reporting manner differed, and outcomes of these studies reflect the effect of the combined interventions. The effects of any individual intervention, however, remain unclear.

Additionally, an expert meeting or literature review before implementing the new reporting manner will likely result in an increase in report quality or accuracy, because the reporter will be guided in stating the correct (newly stated) items necessary for diagnosing when using SR, and thereby enhancing the report content. In this way, confirmation bias can occur, especially when report content quality or accuracy was the main goal of the study, and when outcomes
Fig. 4 Intervention based on SR level. SR level 1, structured layout; SR level 2, structured content
- SR level 1 (44) ㅍ SR level 2 (19)

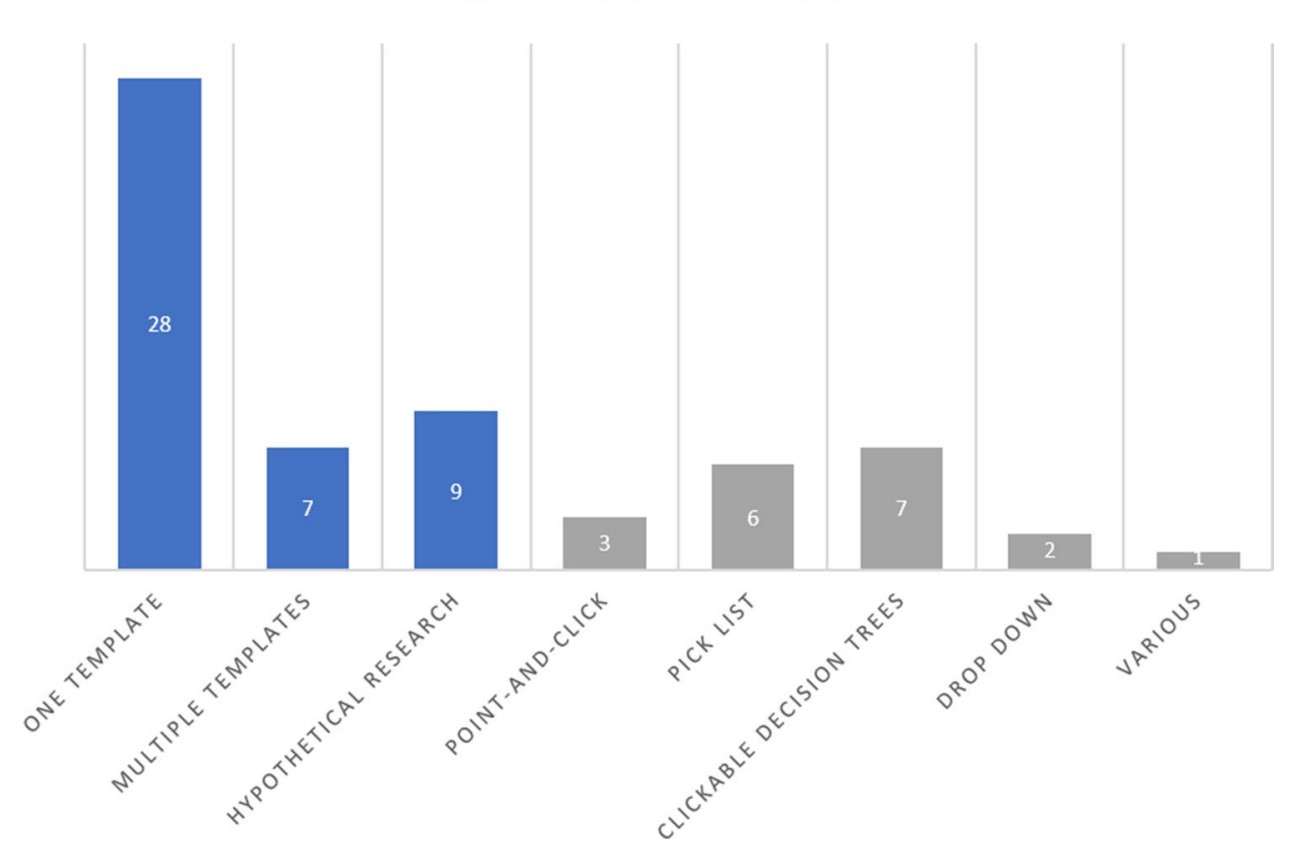


were scored by the same experts that participated in the initial expert meeting.

The aforementioned shows that the study design of the included studies was hampered, resulting in low level of evidence studies. However, despite the fact that most studies are of low evidence, the total amount of published papers show the magnitude of the trend towards structured reporting in radiology.

One of the issues in chosen study design is probably based on the willingness to improve the radiological report
Fig. 5 a Subspecialty based on SR level and (b) modality used based on SR level. All included single intervention studies according to the field of specialty and modality used. SR level 1, structured layout; SR level 2, structured content; DXA, dual-energy X-ray absorptiometry (DXA)

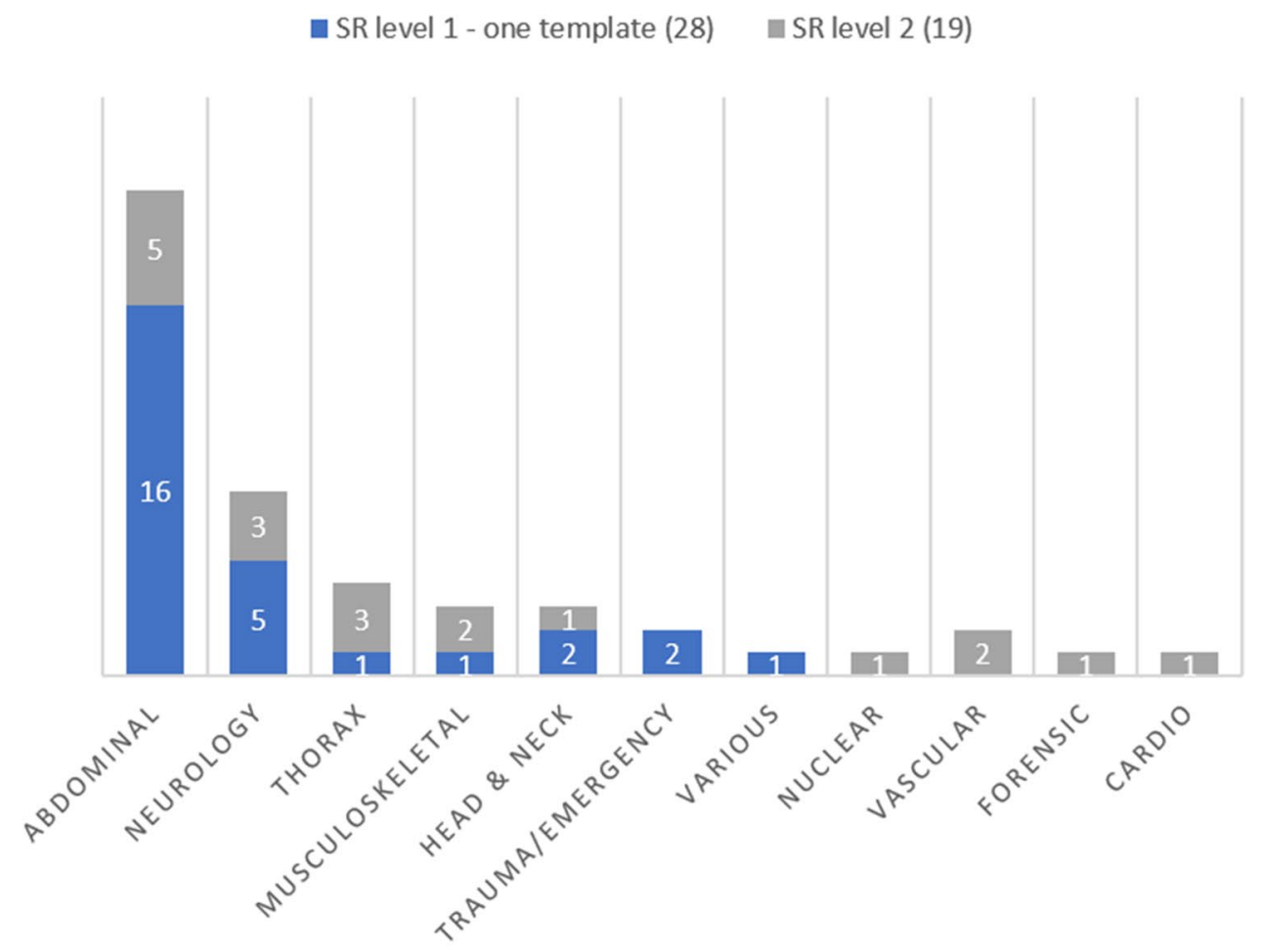

(a)

घR level 1 - one template (28) घ SR level 2 (19)

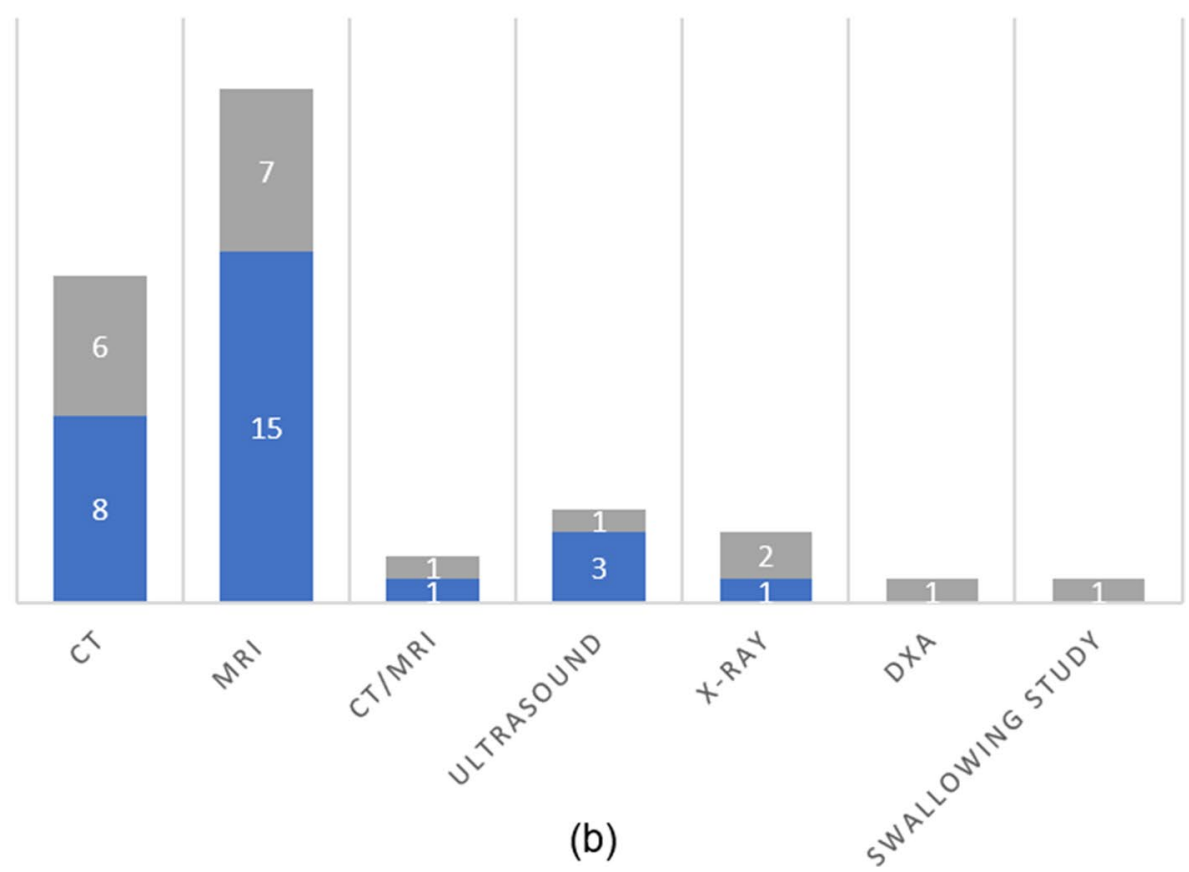


- SR level 1 (44) @ SR level 2 (19)

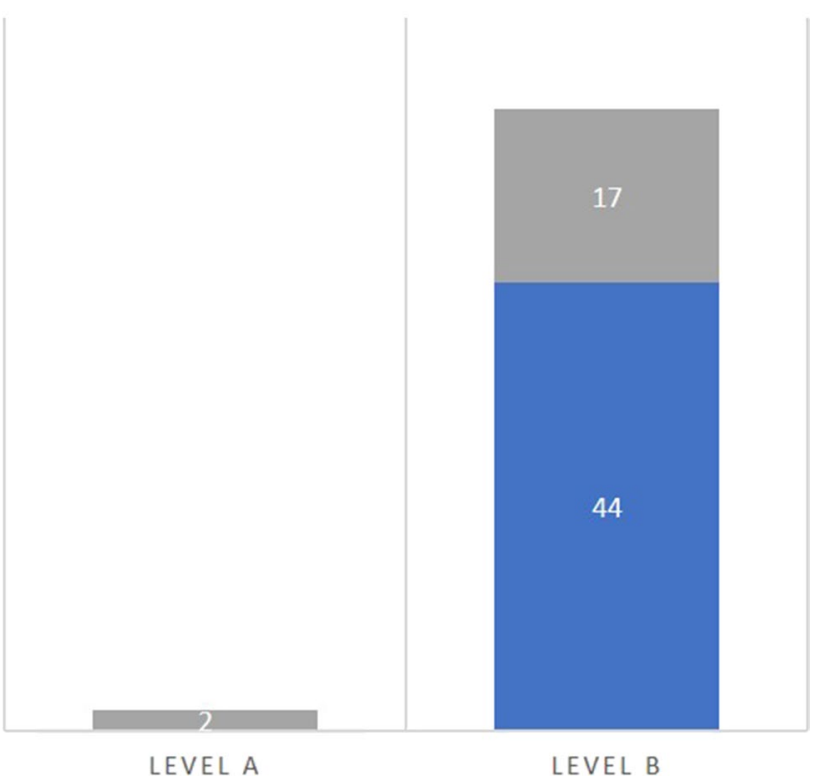

Fig. 6 Level of evidence based on SR level. Level A, level A evidence according to Siwek et al. [13]; SR level 1, structured layout; SR level 2, structured content

as final clinical outcome, rather than searching for the true (single) vehicle that facilitates this.

Furthermore, a reason for the lack of high-level evidence papers can be the fact that proper implementation of SR might be highly case-specific. In radiology, multiple modalities as well as multiple clinical questions coexist and therefore it is possible that a SR tool or a specific SR level is not beneficial for all clinical settings or that it is depending on for instance difficulty level. A point-and-click or clickable decision tree method (SR level 2) may be better for a simple task with only few options, such as describing a thyroid nodule on an ultrasound examination. Likewise, a difficult, extensive clinical question which needs highly specific information or an extensive description, such as the description of a brain tumor on MRI, may suit a template or checklist (SR level 1) better than a point-and-click/pick list. In combination with several vendor-dependent structuring methods on different SR levels, this makes it difficult to choose a specific topic to set up a well-designed study. Also the fact that there are no studies found that compare two different SR methods, but only comparing free text with some sort of SR, shows that research on SR in radiological reporting is still at an exploratory level.

\section{Current standing and future perspectives}

Looking at the levels of SR, in total, 28 studies were performed at the level of structured layout implementing one template and 19 on the structured content level implementing a more IT-based type of SR, which shows that both SR level 1 and 2 are used in clinical studies. It is interesting to see that both levels are being investigated, because it is important to realize that in most cases it is easier, due to its lower IT-demand, to implement a template (SR level 1) in the reporting process than, for instance, implement a dropdown-menu-based report (SR level 2).

When looking at modality and subspecialty, most efforts are made with reports of CT and MRI examinations in the field of abdominal radiology and neuroradiology. An explanation might be the fact that the most important (staging) procedures use CT and MRI as a modality. Perhaps, the abdominal and neuroradiology fields are more suitable for using templates or it can be triggered by the fact that good classification systems or standardization systems already exist in these fields. If this is the case, this highlights the fact that SR is used for standardization by making sure that specific items or classification systems are described or used.

Table 1 shows that SR level 1 (templates) are mainly used to describe key features necessary to stage a particular disease or tumor with a predefined sentence with or without a particular standardization tool. Used standardization tools or classification systems can be found in Table 1, and examples are for instance PI-RADS, LI-RADS and RECIST, but also key elements concerning Crohn's disease, rectal cancer staging, multiple sclerosis (MS), trauma or head and neck lymphadenopathy are used. Hence, also SR level 2 studies use key feature description or standardization tools (e.g., PI-RADS) to describe specific disease or tumors, such as stroke, pulmonary nodules, rectal cancer, thyroid nodules, or prostatic cancer (Table 1). However, SR level 2 studies use an IT-based system that supports constructing (semantic) sentences, according to the chosen option from the dropdown menu or point-and-click system, in which standardization is almost automatically linked to structured reporting.

When looking at the study outcomes in Table 1, the main goals, incentives, used SR method, and outcomes of each study vary widely, and therefore, pooling of outcomes is difficult. Despite this heterogeneity, this table of outcomes provides a panoramic overview of the present status of SR in radiology.

It shows that most of the included papers show an improvement in outcome when implementing SR. However, when looking at the evidence level, the only level A study $[58,59]$ did not improve the report clarity, accuracy, and completeness of the report using their point-and-click method. This is an interesting finding and can show that this particular point-and-click system was not beneficial in radiological reporting in this specific setting and concerning this specific outcome. However, the outcome of this study alone is insufficient to state that SR level 2 is not beneficial in radiology reporting, because outcomes seem to be highly 
case-specific. However, it is also hard to state that SR is beneficial in reporting in radiology when looking at the low level of evidence of all other included studies.

Overall, the level of evidence for SR is low and especially the link between structured reporting and standardization and its different effects on the radiological report is currently overlooked, but is of utmost importance. It seems that improving radiology reporting is more than just implementing SR and that standardization is necessary next to SR, and that both are highly entangled when implementing SR. This is likely caused by the fact that SR is based on a rather strict format in which several (mandatory) items or key features should be reported. Perhaps the question should be whether SR is not just a means to facilitate standardization, rather than that SR is improving the radiological report itself.

As such, high-quality research is necessary to separately investigate the value of all individual factors that are involved in standardization and SR to determine the best type of SR for a specific clinical problem. Investigating the effect of standardization should be prioritized, because it may make sense that improving the content of the report, hence making a complete report with all items referring clinicians are asking for, will likely improve reporting quality. Then, the next question should be how this standardized information should be placed in the radiological report and how we can assure it is inserted correctly. For instance, this can be done with a simple template or checklist (SR level 1), or with a more sophisticated point-and-click system (SR level 2). Finally, it is important to know whether the efforts are beneficial for the patient (e.g., better staging), the referring clinician (e.g., reduced reading time), the reporter (e.g., faster reporting), or for all. Nevertheless, it is possible that this supposed reporting improvement is mainly caused by standardization rather than SR.

\section{Limitations}

First of all, it was difficult to find all relevant implementational studies published on the subject of SR due to ambiguous use of the terms "standardized reporting" and "structured reporting." To be as complete as possible, as well as to answer the research question best, a prior set definition for SR and its categorization system was used. In addition, a bibliography search was used to search for missed studies after conducting the main search. Because of heterogeneity of the included studies, it was hard to pool the data on a more specific level and therefore a thematic analysis was used. The outcome analysis performed in this paper was limited by the large heterogeneity of outcomes and study design. A more thorough analysis should be done to explore outcome measurements better and to see who (the referring clinician, radiologist or patient) will benefit from SR most, as well as which specific efforts resulted in this outcome.

\section{Conclusion}

Structured reporting is thought to have great potential to improve reporting in radiology. However, due to difficulties in study design there is a lack of high-quality research on this topic resulting in low overall evidence. Future research is needed to explore the individual effects of standardization and SR, as it is questionable whether SR is the solution for improving reporting in radiology or only a means in facilitating standardization.

Funding The authors state that this work has not received any funding.

\section{Declarations}

Guarantor The scientific guarantor of this publication is Simon G.F. Robben, MD, PhD.

Conflict of interest The authors of this manuscript declare no relationships with any companies whose products or services may be related to the subject matter of the article.

Statistics and biometry No complex statistical methods were necessary for this paper.

Informed consent Not applicable.

Ethical approval Institutional Review Board approval was not required because the nature of the submitted article.

Methodology

- Systemic literature review

Open Access This article is licensed under a Creative Commons Attribution 4.0 International License, which permits use, sharing, adaptation, distribution and reproduction in any medium or format, as long as you give appropriate credit to the original author(s) and the source, provide a link to the Creative Commons licence, and indicate if changes were made. The images or other third party material in this article are included in the article's Creative Commons licence, unless indicated otherwise in a credit line to the material. If material is not included in the article's Creative Commons licence and your intended use is not permitted by statutory regulation or exceeds the permitted use, you will need to obtain permission directly from the copyright holder. To view a copy of this licence, visit http://creativecommons.org/licenses/by/4.0/.

\section{References}

1. Liu D, Zucherman M, Tulloss WB Jr (2006) Six characteristics of effective structured reporting and the inevitable integration with speech recognition. J Digit Imaging 19:98-104

2. Reiner BI (2009) The challenges, opportunities, and imperative of structured reporting in medical imaging. J Digit Imaging 22:562-568

3. Powell DK, Silberzweig JE (2015) state of structured reporting in radiology, a survey. Acad Radiol 22:226-33

4. Radiological Society of North America (2020) RadReport template library. Radiological Society of North America, Oak Brook 
(IL), USA. Available via https://radreport.org. Accessed 15 Dec 2020.

5. European Society of Radiology (ESR) (2018) ESR paper on structured reporting in radiology. Insights Imaging 9:1-7

6. Schwartz LH, Seymour L, Litière $S$ et al (2016) RECIST 1.1 standardisation and disease-specific adaptations: perspectives from the RECIST Working Group. Eur J Cancer 62:138-145

7. Hansell DM, Bankier AA, MacMahon H, McLoud TC, Müller NL, Remy J (2008) Fleischner Society: glossary of terms for thoracic imaging. Radiology 246:697-722

8. An JY, Unsdorfer KML, Weinreb JC (2019) BI-RADS, C-RADS, CAD-RADS, LI-RADS, Lung-RADS, NI-RADS, O-RADS, PIRADS, TI-RADS: reporting and data systems. Radiographics 39:1435-1436

9. Nobel JM, Kok EM, Robben SGF (2020) Redefining the structure of structured reporting in radiology. Insights Imaging 11:10

10. Moher D, Liberati A, Tetzlaff J, Altman DG; PRISMA Group (2009) Preferred reporting items for systematic reviews and metaanalyses: the PRISMA statement. BMJ 339:b2535

11. Mays N, Pope C, Popay J (2005) Systematically reviewing qualitative and quantitative evidence to inform management and policymaking in the health field. J Health Serv Res Policy 10(Suppl 1):6-20

12. Lucas PJ, Baird J, Arai L, Law C, Roberts HM (2007) Worked examples of alternative methods for the synthesis of qualitative and quantitative research in systematic reviews. BMC Med Res Methodol 7:4

13. Siwek J, Gourlay ML, Slawson DC, Shaughnessy AF (2002) How to write an evidence-based clinical review article. Am Fam Physician 65:251-258

14. Dimarco M, Cannella R, Pellegrino S et al (2020) Impact of structured report on the quality of preoperative CT staging of pancreatic ductal adenocarcinoma: assessment of intra- and inter-reader variability. Abdom Radiol (NY) 45:437-448

15. Gupta NA, Mahajan S, Sumankumar A, Saklani A, Engineer R, Baheti AD (2020) Impact of a standardized reporting format on the quality of MRI reports for rectal cancer staging. Indian J Radiol Imaging 30:7-12

16. McFarland JA, Elkassem AMA, Casals L, Smith GD, Smith AD, Gunn AJ (2021) Objective comparison of errors and report length between structured and freeform abdominopelvic computed tomography reports. Abdom Radiol (NY) 46:387-393

17. Olthof AW, Leusveld ALM, de Groot JC, Callenbach PMC, van Ooijen PMA (2020) Contextual structured reporting in radiology: implementation and long-term evaluation in improving the communication of critical findings. J Med Syst 44(9):148

18. Alessandrino F, Cristiano L, Cinnante CM et al (2019) Value of structured reporting in neuromuscular disorders. Radiol Med (Torino) 124:628-635

19. Benson J, Burgstahler M, Zhang L, Rischall M (2019) The value of structured radiology reports to categorize intracranial metastases following radiation therapy. Neuroradiol J 32:267-272

20. Gore A, Hoch MJ, Shu H-KG, Olson JJ, Voloschin AD, Weinberg BD (2019) Institutional implementation of a structured reporting system: our experience with the brain tumor reporting and data system. Acad Radiol 26:974-980

21. Liu Y, Feng Z, Qin S, Yang J, Han C, Wang X (2019) Structured reports of pelvic magnetic resonance imaging in primary endometrial cancer: potential benefits for clinical decision-making. PLoS One 14(3):e0213928

22. Wetterauer C, Winkel DJ, Federer-Gsponer JR et al (2019) Structured reporting of prostate magnetic resonance imaging has the potential to improve interdisciplinary communication. PLoS One 14(2): 0212444

23. Bink A, Benner J, Reinhardt J et al (2018) Structured reporting in neuroradiology: Intracranial tumors. Front Neurol 9:32
24. Griffin AS, Mitsky J, Rawal U, Bronner AJ, Tessler FN, Hoang JK (2018) Improved quality of thyroid ultrasound reports after implementation of the ACR thyroid imaging reporting and data system nodule lexicon and risk stratification System. J Am Coll Radiol 15:743-748

25. Magnetta MJ, Donovan AL, Jacobs BL, Davies BJ, Furlan A (2018) Evidence-based reporting: a method to optimize prostate MRI communications with referring physicians. AJR Am J Roentgenol 210:108-112

26. Olthof AW, Borstlap J, Roeloffzen WW, Callenbach PMC, van Ooijen PMA (2018) Improvement of radiology reporting in a clinical cancer network: impact of an optimised multidisciplinary workflow. Eur Radiol 28:4274-4280

27. Poullos PD, Tseng JJ, Melcher ML et al (2018) Structured reporting of multiphasic CT for hepatocellular carcinoma: effect on staging and suitability for transplant. AJR Am J Roentgenol 210:766-774

28. Tersteeg JJC, Gobardhan PD, Crolla RMPH et al (2018) Improving the quality of MRI reports of preoperative patients with rectal cancer: effect of national guidelines and structured reporting. AJR Am J Roentgenol 210:1240-1244

29. Flusberg M, Ganeles J, Ekinci T et al (2017) Impact of a structured report template on the quality of CT and MRI reports for hepatocellular carcinoma diagnosis. J Am Coll Radiol 14:1206-1211

30. Franconeri A, Fang J, Carney B et al (2018) Structured vs narrative reporting of pelvic MRI for fibroids: clarity and impact on treatment planning. Eur Radiol 28:3009-3017

31. Pysarenko K, Recht M, Kim D (2017) Structured reporting: a tool to improve reimbursement. J Am Coll Radiol 14:662-664

32. Wildman-Tobriner B, Allen BC, Bashir MR et al (2017) Structured reporting of $\mathrm{CT}$ enterography for inflammatory bowel disease: effect on key feature reporting, accuracy across training levels, and subjective assessment of disease by referring physicians. Abdom Radiol (NY) 42:2243-2250

33. Wildman-Tobriner B, Allen BC, Davis JT et al (2017) Structured reporting of magnetic resonance enterography for pediatric Crohn's disease: effect on key feature reporting and subjective assessment of disease by referring physicians. Curr Probl Diagn Radiol 46:110-114

34. Dickerson E, Davenport MS, Syed F et al; Michigan Radiology Quality Collaborative (2017) Effect of template reporting of brain MRIs for multiple sclerosis on report thoroughness and neurologist-rated quality: results of a prospective quality improvement project. J Am Coll Radiol 14(3):371-379.e1

35. Brook OR, Brook A, Vollmer CM, Kent TS, Sanchez N, Pedrosa I (2015) Structured reporting of multiphasic CT for pancreatic cancer: potential effect on staging and surgical planning. Radiology 274:464-472

36. Sahni VA, Silveira PC, Sainani NI, Khorasani R (2015) Impact of a structured report template on the quality of MRI reports for rectal cancer staging. AJR Am J Roentgenol 205:584-588

37. Silveira PC, Dunne R, Sainani NI et al (2015) Impact of an information technology-enabled initiative on the quality of prostate multiparametric MRI reports. Acad Radiol 22:827-833

38. Lin E, Powell DK, Kagetsu NJ (2014) Efficacy of a checkliststyle structured radiology reporting template in reducing resident misses on cervical spine computed tomography examinations. J Digit Imaging 27:588-593

39. Marcovici PA, Taylor GA (2014) Journal Club: structured radiology reports are more complete and more effective than unstructured reports. AJR Am J Roentgenol 203:1265-1271

40. Powell DK, Lin E, Silberzweig JE, Kagetsu NJ (2014) Introducing radiology report checklists among residents: adherence rates when suggesting versus requiring their use and early experience in improving accuracy. Acad Radiol 21:415-423 
41. Fraser L, O’Neill K, Locke R et al (2013) Standardising reporting of cervical lymphadenopathy in paediatric neck ultrasound: a pilot study using an evidence-based reporting protocol. Int J Pediatr Otorhinolaryngol 77:1248-1251

42. Chung CY, Makeeva V, Yan J et al (2020) Improving billing accuracy through enterprise-wide standardized structured reporting with cross-divisional shared templates. J Am Coll Radiol $17: 157-164$

43. Hanna TN, Shekhani H, Maddu K, Zhang C, Chen Z, Johnson J-O (2016) Structured report compliance: effect on audio dictation time, report length, and total radiologist study time. Emerg Radiol 23:449-453

44. Hawkins CM, Hall S, Zhang B, Towbin AJ (2014) Creation and implementation of department-wide structured reports: an analysis of the impact on error rate in radiology reports. J Digit Imaging 27:581-587

45. Larson DB, Towbin AJ, Pryor RM, Donnelly LF (2013) Improving consistency in radiology reporting through the use of departmentwide standardized structured reporting. Radiology 267:240-250

46. Hawkins CM, Hall S, Hardin J, Salisbury S, Towbin AJ (2012) Prepopulated radiology report templates: a prospective analysis of error rate and turnaround time. J Digit Imaging 25:504-511

47. Schwartz LH, Panicek DM, Berk AR, Li Y, Hricak H (2011) Improving communication of diagnostic radiology findings through structured reporting. Radiology 260:174-181

48. Liu D, Berman GD, Gray RN (2003) The use of structured radiology reporting at a community hospital: a 4-year case study of more than 200,000 reports. Appl Radiol 32:23-26

49. Dabrowiecki A, Sadigh G, Duszak R (2020) Chest radiograph reporting: public preferences and perceptions. J Am Coll Radiol 17:1259-1268

50. Camilo DMR, Tibana TK, Adôrno IF et al (2019) Radiology report format preferred by requesting physicians: prospective analysis in a population of physicians at a university hospital. Radiol Bras 52:97-103

51. Heye T, Gysin V, Boll DT, Merkle EM (2018) Journal Club: structured reporting: the voice of the customer in an ongoing debate about the future of radiology reporting. AJR Am J Roentgenol 211:964-970

52. Lather JD, Che Z, Saltzman B, Bieszczad J (2018) Structured reporting in the academic setting: what the referring clinician wants. J Am Coll Radiol 15:772-775

53. Travis AR, Sevenster M, Ganesh R, Peters JF, Chang PJ (2014) Preferences for structured reporting of measurement data. An institutional survey of medical oncologists, oncology registrars, and radiologists. Acad Radiol 21:785-796

54. Krupinski EA, Hall ET, Jaw S, Reiner B, Siegel E (2012) Influence of radiology report format on reading time and comprehension. J Digit Imaging 25:63-69

55. Grieve FM, Plumb AA, Khan SH (2010) Radiology reporting: a general practitioner's perspective. Br J Radiol 83:17-22

56. Sistrom CL, Honeyman-Buck J (2005) Free text versus structured format: information transfer efficiency of radiology reports. AJR Am J Roentgenol 185:804-812

57. Naik SS, Hanbidge A, Wilson SR (2001) Radiology reports: examining radiologist and clinician preferences regarding style and content. AJR Am J Roentgenol 176:591-598

58. Johnson AJ, Chen MYM, Zapadka ME, Lyders EM, Littenberg B (2010) Radiology report clarity: a cohort study of structured reporting compared with conventional dictation. J Am Coll Radiol 7:501-506

59. Johnson AJ, Chen MYM, Shannon Swan J, Applegate KE, Littenberg B (2009) Cohort study of structured reporting compared with conventional dictation. Radiology 253:74-80

60. Aase A, Fabbrini AE, White KM, Averill S, Gravely A, Melzer AC (2020) Implementation of a standardized template for reporting of incidental pulmonary nodules: feasibility, acceptability, and outcomes. J Am Coll Radiol 17:216-223

61. Alper DP, Shinagare AB, Hashemi SR et al (2020) Effect of a report template-enabled quality improvement initiative on use of preferred phrases for communicating normal findings in structured abdominal CT and MRI reports. AJR Am J Roentgenol 214:835-842

62. Kim SH, Sobez LM, Spiro JE et al (2020) Structured reporting has the potential to reduce reporting times of dual-energy $\mathrm{x}$-ray absorptiometry exams. BMC Musculoskelet Disord 21(1):248

63. Tuncyurek O, Garces-Descovich A, Jaramillo-Cardoso A et al (2019) Structured versus narrative reporting of pelvic MRI in perianal fistulizing disease: impact on clarity, completeness, and surgical planning. Abdom Radiol (NY) 44:811-820

64. Armbruster M, Gassenmaier S, Haack M et al (2018) Structured reporting in petrous bone MRI examinations: impact on report completeness and quality. Int J Comput Assist Radiol Surg 13:1971-1980

65. Sabel BO, Plum JL, Czihal M et al (2018) Structured reporting of CT angiography runoff examinations of the lower extremities. Eur J Vasc Endovasc Surg 55:679-687

66. Schoeppe F, Sommer WH, Haack M et al (2018) Structured reports of videofluoroscopic swallowing studies have the potential to improve overall report quality compared to free text reports. Eur Radiol 28:308-315

67. Schöppe F, Sommer WH, Schmidutz F et al (2018) Structured reporting of $\mathrm{X}$-rays for atraumatic shoulder pain: advantages over free text? BMC Med Imaging 18(1):20

68. Shaish H, Feltus W, Steinman J, Hecht E, Wenske S, Ahmed F (2018) Impact of a structured reporting template on adherence to prostate imaging reporting and data system version 2 and on the diagnostic performance of prostate MRI for clinically significant prostate cancer. J Am Coll Radiol 15:749-754

69. Gassenmaier S, Armbruster M, Haasters F et al (2017) Structured reporting of MRI of the shoulder - improvement of report quality? Eur Radiol 27:4110-4119

70. Norenberg D, Sommer WH, Thasler W et al (2017) Structured reporting of rectal magnetic resonance imaging in suspected primary rectal cancer: potential benefits for surgical planning and interdisciplinary communication. Invest Radiol 52:232-239

71. Sabel BO, Plum JL, Kneidinger N et al (2017) Structured reporting of CT examinations in acute pulmonary embolism. J Cardiovasc Comput Tomogr 11:188-195

72. Walter WR, Goldberg-Stein S, Levsky JM, Cohen HW, Scheinfeld MH (2015) A default normal chest CT structured reporting field for coronary calcifications does not cause excessive false-negative reporting. J Am Coll Radiol 12:783-787

73. Schweitzer W, Bartsch C, Ruder TD, Thali MJ (2014) Virtopsy approach: structured reporting versus free reporting for PMCT findings. J Forensic Radiol Imaging 2:28-33

74. Karim S, Fegeler C, Boeckler D, Schwartz LH, Kauczor H-U, von Tengg-Kobligk H (2013) Development, implementation, and evaluation of a structured reporting web tool for abdominal aortic aneurysms. JMIR Res Protoc 2(2):e30

75. Barbosa F, Maciel LMZ, Vieira EM, Azevedo Marques PM, de, Elias J, Muglia VF, (2010) Radiological reports: a comparison between the transmission efficiency of information in free text and in structured reports. Clinics (Sao Paulo) 65:15-21

76. Hasegawa Y, Matsumura Y, Mihara N et al (2010) Development of a system that generates structured reports for chest $\mathrm{X}$-ray radiography. Methods Inf Med 49:360-370

Publisher's note Springer Nature remains neutral with regard to jurisdictional claims in published maps and institutional affiliations. 